Arq. Bras. Med. Vet. Zootec., v.69, n.1, p.173-180, 2017

\title{
Amendoim forrageiro manejado com baixos resíduos de pastejo por ovinos
}

\author{
[Perennial peanut handled with low grazing waste by sheep] \\ L.A.G. Alonzo, O.G.L. Ferreira*, R.Z. Vaz, O.A.D. Costa, J.F. Motta, W.C. Brondani \\ Faculdade de Agronomia Eliseu Maciel - Universidade Federal de Pelotas - Pelotas, RS
}

\section{RESUMO}

O objetivo do trabalho foi estudar o comportamento produtivo do amendoim forrageiro (Arachis pintoi cv. Amarillo) sob diferentes intensidades de pastejo por ovinos em ambiente rotativo. Os tratamentos corresponderam a quatro intensidades de pastejo (muito leniente $-\mathrm{ML}$, leniente $-\mathrm{L}$, moderado $-\mathrm{M}$ e severo - S) representadas pelas alturas de resíduo de 11,$2 ; 8,4 ; 5,9$ e 3,2cm, que foram alocadas segundo um delineamento inteiramente ao acaso, com quatro repetições. As variáveis estudadas no pré e no póspastejo foram: massa de forragem, percentual de folhas e caules e índice de área foliar. Ao final do experimento, foi calculada a massa de forragem total acumulada, a taxa de acúmulo e a massa de forragem desaparecida. Os dados foram submetidos à análise de variância e ao teste de comparação de médias de Tukey $(\mathrm{P}<0,05)$. Foi verificado que a intensidade de pastejo modifica a composição dos componentes morfológicos e a massa de forragem acumulada pelo amendoim forrageiro, todavia o índice de área foliar no pré-pastejo não é alterado. $\mathrm{O}$ amendoim forrageiro não deve ser utilizado sob pastejo intenso. Intensidades de pastejo de moderada a muito leniente proporcionam maior massa de forragem pré-pastejo e total acumulada, associada a menores intervalos entre pastejos.

Palavras-chave: Arachis pintoi, leguminosa forrageira, lotação rotacionada, resíduo de pastejo

\begin{abstract}
This research aimed to study the productive behavior of perennial peanut (Arachis pintoi cv. Amarillo) under different grazing intensities by sheep in a rotation environment. The treatments consisted of four grazing intensity levels (very lenient - VL, lenient - $L$, moderate $-M$, and severe - $S$ ) represented by the residues 11.2; 8.4; 5.9 and $3.2 \mathrm{~cm}$, and allocated randomly with four replications. The variables studied in the pre-grazing and post-grazing were: forage mass, percentage of leaves and stems and leaf area index. At the end of the experiment, total accumulated forage mass, accumulation rate, and mass of missing forage were calculated. The data was submitted to a variance analysis and comparison to a Tukey's test, with a 5\% significance level. Grazing intensity was found to modify the composition of morphological components and the forage mass accumulated by peanuts; however, the leaf area index in pre-grazing remained constant. Perennial peanut should not be used under intensive grazing. Grazing intensity from moderate to very lenient provides greater mass of pre-grazing forage and total accumulated forage, combined with shorter intervals between grazing.
\end{abstract}

Keywords: Arachis pintoi, forage legume, rotational stocking, grazing residue

\section{INTRODUÇÃO}

A fim de ultrapassar os problemas relativos à baixa qualidade nutricional das forragens, normalmente os produtores fornecem alimentos concentrados aos animais, elevando assim os custos de produção. Nesse sentido, faz-se

Recebido em 9 de maio de 2016

Aceito em 20 de junho de 2016

*Autor para correspondência (corresponding author)

E-mail: oglferreira@gmail.com necessário usar mais intensamente e racionalmente espécies forrageiras de alta produtividade e valor nutritivo, suprindo deficiências das pastagens a baixo custo.

A utilização de leguminosas pode ser uma opção para a melhoria da qualidade forrageira, já que traz benefícios técnicos, econômicos e 
ambientais aos sistemas pecuários, tanto quando em consórcio com gramíneas, quanto em cultivo singular. Dentre as leguminosas estivais, o amendoim forrageiro (Arachis pintoi) se destaca por ser uma espécie herbácea perene, de alto valor nutritivo, com crescimento rasteiro e hábito estolonífero, bem adaptado a solos de baixa a média fertilidade e tolerante àqueles com alta saturação por alumínio. Possui a vantagem de ter os pontos de crescimento bem protegidos do pastejo, apresentando grande persistência e adaptação às condições de sombreamento (Rao et al.,1995; Argel et al., 2005).

Em geral, os resultados de pesquisas já identificaram que o ponto ideal para o início da colheita da forragem é quando o dossel forrageiro atinge condição capaz de interceptar cerca de $95 \%$ da luz incidente (Amaral et al., 2013), todavia o limite inferior da desfolha, ou seu resíduo, para muitas espécies forrageiras ainda necessita ser determinado. $\mathrm{O}$ emprego da incorreta frequência e intensidade de desfolha pode resultar em menor produtividade da pastagem, assim como na formação de estruturas inadequadas ao pastejo, caracterizadas por maiores acúmulos de colmo e de tecidos mortos (Barbosa et al., 2007).

Conforme Carvalho et al. (2009), para gramíneas, as desfolhas devem ser realizadas com intensidades "moderadas", resultando em um resíduo em torno de $50 \%$ da altura prépastejo. Entretanto, para algumas forrageiras, como o Arachis pintoi, espécie que possui os pontos de crescimento protegidos, a intensidade ideal de desfolha para distintos ambientes ainda não é conhecida. Dessa forma, o objetivo do presente trabalho foi estudar o comportamento produtivo do amendoim forrageiro (Arachis pintoi cv. Amarillo) sob diferentes intensidades de pastejo por ovinos em ambiente rotativo.

\section{MATERIAL E MÉTODOS}

O experimento foi conduzido no Centro Agropecuário da Palma/UFPEL, localizado no $\mathrm{km} 535$ da BR 116, a $31^{\circ} 52^{\prime} \mathrm{S}$ e $52^{\circ} 29^{\prime} \mathrm{W}$, na altitude de $13,24 \mathrm{~m}$, região fisiográfica Litoral Sul do Rio Grande do Sul.

O clima da região é do tipo subtropical úmido, Cfa, segundo a classificação Köppen. O solo da área experimental é classificado como Argissolo
Vermelho-Amarelo eutrófico típico, unidade de mapeamento Camaquã. $\mathrm{Na}$ análise química o solo apresentou as seguintes características: $\mathrm{pH}$ água=5,8; $\mathrm{MO}=1,2(\%) ; \mathrm{P}=4,2\left(\mathrm{mg}_{3} \mathrm{dm}^{-3}\right) ; \mathrm{K}=40$ $\left(\mathrm{mg} \cdot \mathrm{dm}^{-3}\right) ; \quad \mathrm{Ca}=3,0 \quad\left(\mathrm{cmol}_{\mathrm{c}} \cdot \mathrm{dm}^{-3}\right) ; \quad \mathrm{Mg}=1,6$ $\left(\mathrm{cmol}_{\mathrm{c}} \cdot \mathrm{dm}^{-3}\right) ; \mathrm{Al}=0,2\left(\mathrm{cmol}_{\mathrm{c}} \cdot \mathrm{dm}^{-3}\right) ;$ CTCefetiva $=$ $4,9\left(\mathrm{cmol}_{\mathrm{c}} \cdot \mathrm{dm}^{-3}\right)$ e saturação de bases de $70 \%$.

O experimento foi conduzido em área estabelecida com amendoim forrageiro (Arachis pintoi cv. Amarillo) em novembro de 2001. Desse momento até o começo do experimento, a pastagem era utilizada para pastejo de bovinos leiteiros e equinos. Durante o inverno era sobressemeada com azevém anual (Lolium multiflorum Lam.).

A área experimental de 0,29 ha foi dividida em 16 piquetes de $180 \mathrm{~m}^{2}$, onde foram alocadas, em delineamento inteiramente ao acaso, com quatro repetições, as intensidades de pastejo representadas pelas alturas de resíduo 11,$2 ; 8,4$; 5,9 e $3,2 \mathrm{~cm}$, obtidas a partir das alturas pretendidas de 11,$2 ; 8,4 ; 5,6$ e 2,8cm, equivalentes às intensidades muito leniente (ML), leniente (L), moderada (M) e severa (S), respetivamente. Estas alturas de resíduo são derivadas do rebaixamento de 20, 40, 60 e $80 \%$ da altura pré-pastejo $(14 \mathrm{~cm})$.

No início da primavera de 2014, foi realizado corte de uniformização da área, seguido de controle de invasoras por arranquio manual. A área foi roçada e usou-se herbicida seletivo de ação sistêmica à base de fluazifop-P-butílico i.a., na dose de $250 \mathrm{~g} / \mathrm{L}$ ha $^{-1}$. Também foi realizada adubação com $120 \mathrm{~kg} \cdot \mathrm{ha}^{-1}$ da fórmula 05-30-10, baseada no resultado da análise do solo e na recomendação do Manual... (2004) para leguminosas forrageiras de estação quente.

A partir desse momento, a pastagem foi monitorada semanalmente quanto à altura do dossel, ao índice de área foliar e à respectiva massa de forragem, sendo o primeiro pastejo definido por sua estabilização, o que se deu aos $14 \mathrm{~cm}$ de altura, IAF médio de 3,6 e massa de forragem média de $3776 \mathrm{~kg} \cdot \mathrm{ha}^{-1}$. Em ambiente de pastejo rotativo, os animais eram retirados dos piquetes quando as alturas de resíduos propostas eram atingidas, e retornavam a estes quando a pastagem alcançava novamente $14 \mathrm{~cm}$ de altura. A avaliação de altura do dossel era realizada utilizando-se um disco medidor de pastagens 
(rising meter plate). Os pontos de amostragem foram definidos de forma aleatória, toralizando 30 leituras de altura por unidade experimental.

Em local representativo da altura média de cada piquete no pré-pastejo e no pós-pastejo, foi realizada a amostragem da forragem com quadro de $0,25 \mathrm{~m}^{2}$. A forragem foi cortada ao nível do solo para determinação da massa seca de forragem (MF) e separação dos componentes morfológicos da pastagem \{folíolos e caules (caules+pecíolos+peciólulos) \}.

Após a separação, a área dos folíolos foi determinada em integrador de área foliar modelo LI-3100 (Li-Cor, Lincoln, Nebraska, EUA). Os valores de IAF foram calculados a partir do quociente entre a área foliar da amostra e a área correspondente de amostragem. As amostras de forragem foram pesadas e levadas à estufa de circulação forçada de ar a $55^{\circ} \mathrm{C}$, até massa constante. Também foram avaliadas: massa de forragem desaparecida = diferença entre a MF no pré-pastejo e a MF no pós-pastejo; taxa de acúmulo = valor da MF no primeiro pré-pastejo + (somatório das MF pré-pastejo - MF póspastejo anterior), dividido pelo número de dias entre pastejos; massa de forragem total acumulada $=$ somatório das MF acumuladas em cada intervalo entre pastejos. Nos tratamentos
Muito Leniente e Moderado, acrescentou-se a MF destes no dia final dos pastejos nos tratamentos Severo e Leniente, com o objetivo de propiciar a todos o mesmo período de crescimento da forragem.

Os dados foram submetidos à análise de variância e as médias comparadas pelo teste de Tukey, a 5\% de significância. Todas as análises foram realizadas com uso do pacote estatístico SAS $^{\circledR}$ (Statistical Analysis System), versão 9.0 para Windows ${ }^{\circledR}$.

\section{RESULTADOS E DISCUSSÃO}

As diferentes intensidades de pastejo proporcionaram distintos níveis de aproveitamento da pastagem (Tab. 1). Nas intensidades muito leniente (ML) e leniente (L), foi possível a realização de maior número de pastejos durante os 75 dias do período experimental. Nas intensidades moderada (M) e severa $(\mathrm{S})$, realizaram-se apenas dois pastejos, com intervalos de 38 e 58 dias, respectivamente. Ou seja, para semelhante carga animal e área de pastejo diário seriam necessários 2,5 vezes mais piquetes (35) utilizando-se um pastejo ML do que ao se utilizar o pastejo $S$, que necessitaria de somente 14 piquetes para cumprir o ciclo de pastejo.

Tabela 1. Caracterização das desfolhas (pastejos e corte final) de amendoim forrageiro sob intensidades de pastejo

\begin{tabular}{|c|c|c|c|c|}
\hline \multirow{2}{*}{ Variável } & \multicolumn{4}{|c|}{ Intensidades de pastejo } \\
\hline & ML & $\mathrm{L}$ & $\mathrm{M}$ & $\mathrm{S}$ \\
\hline Número de pastejos & 4 & 3 & 2 & 2 \\
\hline Intervalo entre pastejos (dias) & 20 & 34 & 38 & 58 \\
\hline Intervalo entre pastejos (GD) & 163,8 & 307,6 & 311,2 & 523,9 \\
\hline $\begin{array}{c}\text { Data dos pastejos ou corte } \\
\text { final }\end{array}$ & $\begin{array}{c}09 / 01 ; 30 / 01 ; \\
13 / 02 ; 11 / 03 \mathrm{e} \\
24 / 03^{*}\end{array}$ & $\begin{array}{l}09 / 01 ; 13 / 02 \\
\text { e } 20 / 03\end{array}$ & $\begin{array}{l}09 / 01 ; 18 / 02 \\
\text { e } 24 / 03^{*}\end{array}$ & $09 / 01$ e $12 / 03$ \\
\hline $\begin{array}{l}\text { Período de ocupação (dias - } \\
\text { horas) }\end{array}$ & $0,6 \mathrm{~d}-14,0 \mathrm{~h}$ & $1,3 d-30,3 h$ & $2,3 d-55,6 h$ & $4,5 \mathrm{~d}-108,0 \mathrm{~h}$ \\
\hline Carga animal (kg.180m $\left.{ }^{2-1}\right)$ & 290 & 294,7 & 298 & 285,4 \\
\hline Peso corporal médio (kg) & 48,3 & 49,1 & 49,7 & 47,6 \\
\hline Lotação (ovinos. $180 \mathrm{~m}^{2-1}$ ) & 6 & 6 & 6 & 6 \\
\hline
\end{tabular}

Todavia, não somente o número de piquetes e, consequentemente, a área de pasto disponível devem ser considerados na escolha da intensidade de manejo da pastagem. Também são importantes, entre outras, variáveis de produtividade global do sistema, quantidade e qualidade da forragem desaparecida, comportamento animal em pastejo e persistência da pastagem. Cabe ressaltar ainda que o intervalo entre pastejos nas intensidade L e M foi próximo (quatro dias de diferença), e que esta última intensidade não sofreu nova desfolha 
provavelmente em razão do déficit hídrico registrado após o último pastejo (18/02), quando as precipitações pluviométricas ocorridas ficaram abaixo das normais da região.

Maior massa de forragem no pré-pastejo foi encontrada nas menores intensidades (Tab. 2), apesar de todos os tratamentos terem a mesma altura pré-pastejo $(14 \mathrm{~cm})$ e massa inicial média de 3776 kg.ha ${ }^{-1}$. Isso denota alterações na arquitetura das plantas e, consequentemente, na distribuição das frações folha e caule. Desse modo, em razão de compensações entre estas, a massa de forragem se mostrou semelhante entre os tratamentos ML, L e M e; L, M e S. É importante ressaltar que, nos tratamentos $\mathrm{ML}, \mathrm{L}$ e $\mathrm{M}$, os valores médios de massa de forragem pré-pastejo foram superiores à massa de forragem inicial, todavia com mesma altura $(14 \mathrm{~cm})$. Tais variações podem ser provenientes de alterações no hábito de crescimento das plantas, prioritariamente prostrado, em consequência do método de pastejo empregado.

Tabela 2. Massa de forragem (MF), percentual de folhas e caules e índice de área foliar (IAF) no pré e pós-pastejo de amendoim forrageiro sob intensidades de pastejo

\begin{tabular}{|c|c|c|c|c|}
\hline Intensidade de pastejo & $\begin{array}{c}\text { MF } \\
\left(\mathrm{kg} \mathrm{ha}^{-1}\right)\end{array}$ & $\begin{array}{c}\text { Folhas } \\
(\%)\end{array}$ & $\begin{array}{c}\text { Caules } \\
(\%)\end{array}$ & IAF \\
\hline \multicolumn{5}{|c|}{ Pré-pastejo } \\
\hline ML & $4504 \mathrm{a}$ & $46,6 \mathrm{ab}$ & $53,4 \mathrm{ab}$ & 3,7 \\
\hline $\mathrm{L}$ & $4464 \mathrm{ab}$ & $45,5 \mathrm{~b}$ & $54,5 \mathrm{a}$ & 3,6 \\
\hline M & $4312 \mathrm{ab}$ & $42,2 \mathrm{~b}$ & $57,8 \mathrm{a}$ & 3,5 \\
\hline $\mathrm{S}$ & $3679 \mathrm{~b}$ & $52,0 \mathrm{a}$ & $48,0 \mathrm{~b}$ & 3,3 \\
\hline Média & 4240 & 46,6 & 53,4 & 3,5 \\
\hline $\mathrm{CV}$ & 9,0 & 6,5 & 5,7 & 19,1 \\
\hline \multicolumn{5}{|c|}{ Pós-pastejo } \\
\hline ML & $3636 \mathrm{a}$ & $35,3 \mathrm{a}$ & $64,7 \mathrm{c}$ & $2,7 \mathrm{a}$ \\
\hline $\mathrm{L}$ & $3553 \mathrm{a}$ & $33,4 \mathrm{a}$ & $66,6 \mathrm{c}$ & $2,4 \mathrm{a}$ \\
\hline M & $2810 \mathrm{~b}$ & $23,0 \mathrm{~b}$ & $77,0 \mathrm{~b}$ & $1,4 \mathrm{~b}$ \\
\hline $\mathrm{S}$ & $1793 \mathrm{c}$ & $5,0 \mathrm{c}$ & $95,0 \mathrm{a}$ & $0,1 \mathrm{c}$ \\
\hline Média & 2948 & 24,2 & 75,8 & 1,7 \\
\hline $\mathrm{CV}$ & 8,7 & 14,1 & 4,5 & 23,8 \\
\hline
\end{tabular}

Médias seguidas de mesma letra na coluna, no pré ou pós-pastejo, não diferem estatisticamente para o teste de Tukey $(\mathrm{P}<0,05) . \mathrm{ML}=11,2 \mathrm{~cm} ; \mathrm{L}=8,4 \mathrm{~cm} ; \mathrm{M}=5,9 \mathrm{~cm} ; \mathrm{S}=3,2 \mathrm{~cm}$.

Maior percentual de folhas, por sua vez, foi registrado na intensidade de pastejo $\mathrm{S}$ (Tab. 2), fato que provavelmente decorre da maior exposição dos pontos de crescimento à luz pela abertura do dossel forrageiro, o que induz à emissão de folhas. Além disso, segundo Fialho (2015), o amendoim forrageiro, quando é submetido a maiores intensidades de pastejo, registra maiores taxas de aparecimento de folhas e de alongamento de pecíolos e o menor tamanho de folhas, ou seja, as plantas investem na produção de maior número de folhas pequenas.

Para a fração caules, inversamente à fração folhas, seus maiores percentuais foram verificados nas menores intensidades de pastejo; neste caso, principalmente como reflexo da adapatação das plantas em busca de luz. Esses resultados são confirmados pelos obtidos por
Fialho (2015), que, ao avaliar amendoim forrageiro cv. Belmonte, verificou elevada disponibilidade de luz nos tratamentos mantidos mais baixos. Por outro lado, nos tratamentos mantidos mais altos, a disponibilidade de luz era restrita, razão pela qual as plantas investiram em crescimento de estolões (parte aérea) como forma de buscar maior quantidade de luz. Além disso, na intensidade de pastejo $\mathrm{S}$ do presente estudo, os animais, após removerem as folhas, passavam a também remover caules em grande quantidade, não sendo estes repostos até o novo pastejo. Nas intensidades menores, por sua vez, houve menor consumo dessas estruturas, tendo em vista os animais priorizarem a remoção de folhas em relação a caules (L'Huillier et al., 1986; Gonçalves, 1999). Esses resultados vão ao encontro do citado por Carvalho et al. (1999). Segundo estes, para o verdadeiro conhecimento 
dos fatores envolvidos na interface plantaanimal, a simples quantificação das alturas e das massas de forragem não é suficiente para esclarecer todas as respostas produtivas, visto ser possível encontrar a mesma massa de forragem com infinitas combinações de altura, densidade e composição.

O IAF do pré-pastejo $(14 \mathrm{~cm})$ manteve-se com média de 3,5, independentemente da intensidade de pastejo empregada $(\mathrm{P}>0,05)$. Esses resultados decorrem da plasticidade fenotípica do amendoim forrageiro, havendo compensação entre o tamanho e a proporção de folhas presentes na massa de forragem. Ou seja, para um mesmo IAF é possível encontrar folíolos maiores ou menores, dependendo da intensidade de pastejo empregada. Segundo Fialho (2015), como estratégia de otimização do IAF, plantas de amendoim forrageiro sob menor intensidade de pastejo investem na produção de menor número de folhas grandes. Quando submetidas a maiores intensidades, investem na produção de maior número de folhas pequenas. Essas afirmações explicam os resultados do presente estudo, no qual, na intensidade de pastejo $\mathrm{S}$, observavam-se folíolos pequenos, enquanto sob intensidade ML e L, folíolos grandes. Ainda de acordo com Fialho (2015), essa estratégia para manutenção do IAF faz com que o perfil da população de plantas seja mais jovem e com menor número de folhas maduras. Dessa forma, mesmo valor de IAF pode resultar em potenciais distintos de produção de forragem, uma vez que existe variação no perfil de idade das folhas que compõem o dossel forrageiro, com implicações sobre a eficiência fotossintética (Parsons et al., 1988).

Valores semelhantes foram relatados por Carvalho (2014) para o Arachis pintoi cv. Belmonte. Segundo este autor, a interceptação de 95\% da luz incidente ocorreu entre as alturas de manejo de 10 e $15 \mathrm{~cm}$, com IAF variando de 3,5 a 4,1. Gobbi et al. (2009), ao mensurarem o IAF do cv. Amarillo, também com $95 \%$ de interceptação da luz incidente, observaram IAF de 2,7 , com altura entre 8,7 e $12,7 \mathrm{~cm}$.

No pós-pastejo, verificaram-se diferenças significativas na massa de forragem, no percentual de folhas e de caules e no índice de área foliar entre as intensidades de pastejo (Tab. 2). Maiores valores de massa de forragem pós- pastejo foram registrados nos tratamentos com alturas de resíduo maiores. Os valores de massa de forragem variaram de $1793 \mathrm{~kg} \cdot \mathrm{ha}^{-1}$, quando a pastagem foi manejada na intensidade $\mathrm{S}$ (altura de resíduo de $3,2 \mathrm{~cm}$ ), a $3636 \mathrm{~kg} \cdot \mathrm{ha}^{-1}$, quando manejada na intensidades ML, com altura de resíduo de $11,2 \mathrm{~cm}$. Esses valores são inferiores aos relatados por Carvalho (2014) para Arachis pintoi cv. Belmonte manejado sob lotação contínua $(5680 \mathrm{~kg} /$ ha para altura média de $5 \mathrm{~cm}$ e $8560 \mathrm{~kg} \cdot \mathrm{ha}^{-1}$ para altura de $\left.10 \mathrm{~cm}\right)$. Em contrapartida, no manejo moderado $(5,9 \mathrm{~cm})$, os valores são semelhantes aos obtidos por Valentim et al. (2003) na mesma espécie e cultivar $\left(2373 \mathrm{~kg} \cdot \mathrm{ha}^{-1}\right.$; altura média de $\left.6,2 \mathrm{~cm}\right) \mathrm{e}$ por Menezes et al. (2012) para um conjunto de cultivares de $A$. pintoi e $A$. repens $\left(2672 \mathrm{~kg} \mathrm{ha}^{-1}\right.$; altura média de $6,1 \mathrm{~cm})$.

A massa de forragem pós-pastejo (MF), o percentual de folhas e o índice de área foliar (IAF) mostraram mesmo comportamento, apresentando maiores valores nas intensidades de pastejo ML e L. Menores valores dessas variáveis foram registrados na intensidade $\mathrm{S}$. Ou seja, na medida em que aumenta a intensidade de pastejo, diminui a forragem residual, assim como $o$ percentual de folhas remanescentes e, consequentemente, o IAF (Tab. 2).

Nas intensidades $\mathrm{M}$ e $\mathrm{S}$ a remoção de folhas foi superior a $77 \%$, fato que levou a consequências negativas no rebrote das plantas e a maior tempo necessário para o próximo pastejo, tendo em vista o baixo IAF residual. Conforme Lemaire (1997), esta variável é importante para a eficiência de absorção luminosa, a capacidade fotossintética do relvado e, consequentemente, para a produtividade da pastagem.

A composição botânica de uma pastagem é grandemente influenciada por sua altura. A massa de forragem residual proporciona alterações na participação e disposição dos componentes folha, caule e material senescente e, assim, modifica a quantidade e a qualidade da forragem disponível ao pastejo (Stobbs et al., 1975). Em pastejo rotativo, alterações na estrutura do dossel, à medida que o pasto é rebaixado, podem provocar modificações na composição da forragem consumida (Trindade $e t$ al., 2007). Os últimos autores relataram ainda, que, como a proporção de folhas do resíduo póspastejo é inferior àquela da massa de forragem 
em pré-pastejo, há maior dificuldade de colheita de folhas pelos animais à medida que os estratos superiores vão sendo colhidos.

Ao contrario do ocorrido com a fração caule no pré-pastejo, no pós-pastejo seus maiores percentuais foram verificados nas maiores intensidades de pastejo (Tab. 2). Isso se deve à maior remoção de folhas à medida que a intensidade de pastejo aumenta, restando na massa de forragem residual predominantemente caules. Nessa situação, provavelmente os animais pastejam sítios de baixa oferta de forragem, de forma quase não seletiva, consumindo, assim, biomassa de menor qualidade. Segundo Prache e Peyraud (1997), a qualidade da dieta não depende somente do potencial qualitativo da pastagem, mas também da possibilidade e capacidade do animal de selecionar uma dieta de alto valor nutritivo. Nesse sentido, Rattray et al. (1987) acreditam que uma pastagem com massa de forragem inferior a 2000kg.ha ${ }^{-1}$ de MS dificulte o pastejo de ovinos, situação essa que, no presente estudo, ocorreu apenas no tratamento de intensidade $\mathrm{S}$.

Após cada pastejo, os valores de índice de área foliar (IAF) remanescente diminuíram à medida que a intensidade de pastejo foi maior. $\mathrm{Na}$ intensidade $\mathrm{S}$, a maior desfolhação a que as plantas foram submetidas levou à eliminação de folhas com alto potencial fotossintético e pontos de crescimento, registrando-se o menor IAF dentre as intensidades de pastejo avaliadas, fato que determinou o prolongamento do período de recuperação das plantas e, consequentemente, maior intervalo entre pastejos. Nesse sentido, Parsons e Chapman (2000) afirmam que, sob alta intensidade de pastejo, por causa da diminuição do índice de área foliar, há redução da fotossíntese do dossel pela remoção excessiva de lâminas foliares fotossinteticamente ativas. Nessa situação há necessidade de utilização de carboidratos de reserva para a recomposição da parte aérea, indicando maior demanda de tempo para novo corte (Da Silva et al., 2010).

A taxa de acúmulo (TA) não variou significativamente entre os tratamentos, com média de $53,5 \mathrm{~kg}$ de MS ha ${ }^{-1} \cdot$ dia $^{-1}$. Obteve-se valor elevado para essa variável quando comparado ao relatado por Urbano et al. (2010) para cv. Amarillo, 26kg de MS ha ${ }^{-1} \cdot \mathrm{dia}^{-1}$ e por
Valentim et al. (2003) para cv. Belmonte, $20 \mathrm{~kg}$ de MS.ha ${ }^{-1} \cdot$ dia $^{-1}$. Porém, valores semelhantes aos do presente estudo foram obtidos no cv. Amarillo por Teixeira et al. (2010) e em outros quatro genótipos de amendoim forrageiro por Ferreira (2014), demonstrando, segundo este autor, a capacidade de rebrota da espécie mesmo em intervalos de cortes menores.

A massa de forragem total acumulada (MFTA) e a massa de forragem desaparecida (MFD) variaram com as diferentes intensidades de desfolha adotadas (Fig. 1). Provavelmente, os altos IAFs e as massas de forragem a que os tratamentos ML e L foram submetidos limitaram seu potencial de acúmulo de forragem. Assim, a MFTA só se mostrou diferente entre os tratamentos $\mathrm{S}$ e $\mathrm{M}$, com valores que variaram de 6194 a $7967 \mathrm{~kg} \cdot \mathrm{ha}^{-1}$, respectivamente, e média de $7135 \mathrm{~kg} \cdot \mathrm{ha}^{-1}$ entre as quatro intensidades de pastejo.

Valor semelhante de rendimento total de forragem foi observado por Machado et al. (2005), 7132kg.ha-1, Affonso et al. (2007), 6429kg.ha- ${ }^{-1}$, e Nascimento et al. (2010), $6000 \mathrm{~kg} \cdot \mathrm{ha}^{-1}$, quando trabalharam com cv. Alqueire $^{-1}$ em diferentes solos do sul do Rio Grande do Sul. Por sua vez, Ferreira (2014), ao avaliar o desempenho de genótipos de amendoim forrageiro no Estado de São Paulo, verificou rendimentos de até $4900 \mathrm{~kg} \cdot \mathrm{ha}^{-1}$ para o cv. Amarillo, 5000kg.ha- ${ }^{-1}$ para o cv. Mandobi, $5200 \mathrm{~kg} \cdot \mathrm{ha}^{-1}$ para o cv. Alqueire ${ }^{-1}$ e $8400 \mathrm{~kg} \cdot \mathrm{ha}^{-1}$ para o cv. Belmonte.

Maior massa de forragem desaparecida (MFD) foi observada na intensidade S (Fig. 1), todavia, em razão do maior período de ocupação do piquete, a oferta de forragem média nesse tratamento foi de somente $2,64 \%$ do peso vivo (PV), o que provavelmente resultou em restrição do consumo. Além disso, essa intensidade de pastejo disponibilizou aos animais forragem com elevada participação de caules, não permitindo que exercessem sua capacidade de seleção. Importante mencionar ainda, que nem toda a forragem considerada desaparecida foi consumida, tendo em vista que o desaparececimento de forragem também pode advir da senescência, do material verde tombado e pisoteado pelos animais e da queda dos bocados. 


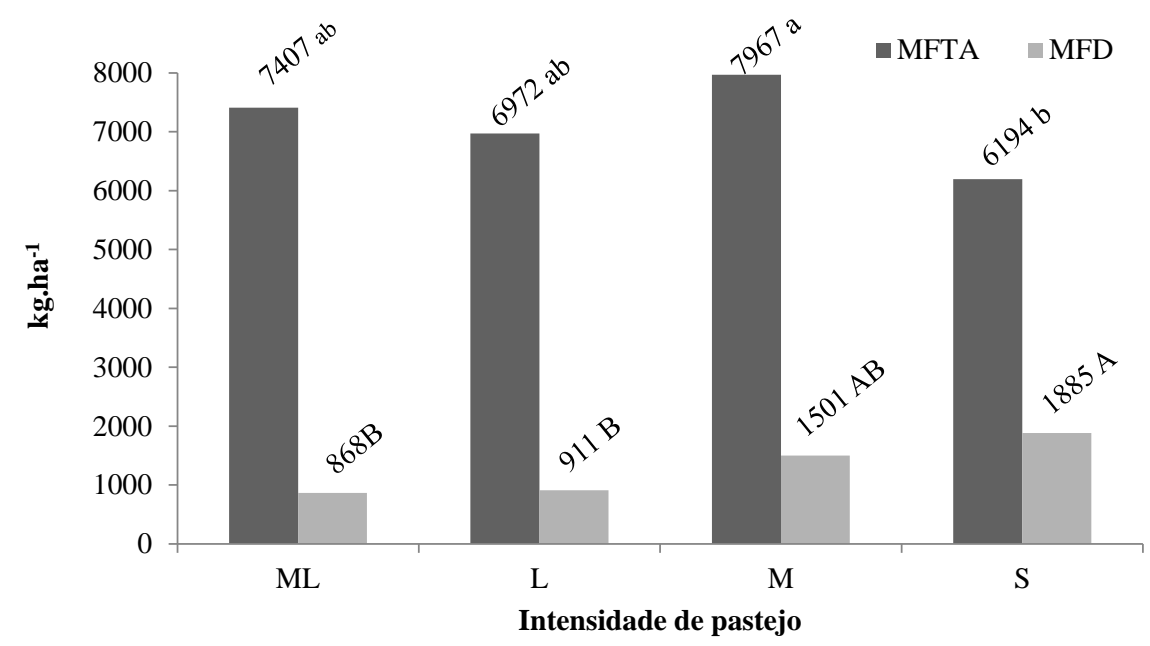

*Médias seguidas de mesma letra, minúscula para MFTA e maiúscula para MFD, não diferem estatisticamente para o teste de Tukey $(\mathrm{P}<0,05) . \mathrm{ML}=11,2 \mathrm{~cm} ; \mathrm{L}=8,4 \mathrm{~cm} ; \mathrm{M}=5,9 \mathrm{~cm} ; \mathrm{S}=3,2 \mathrm{~cm}$.

Figura 1. Massa de forragem total acumulada (MFTA) e massa de forragem desaparecida (MFD) de amendoim forrageiro sob intensidades de pastejo.

Nas intensidades de pastejo L e M, a oferta foi de 4,42 e $3,91 \%$ do PV, respectivamente, enquanto na intensidade ML, os animais tinham à sua disposição uma oferta de $9,29 \%$ do PV, permitindo a plena seleção da melhor forragem. Nesse sentido, o Nutrient... (2006) informa que, para o animal exercer sua máxima capacidade de ingestão, é necessário que seja oferecida quantidade de forragem no mínimo três vezes superior ao seu potencial de consumo.

\section{CONCLUSÕES}

A intensidade de pastejo modifica a composição dos componentes morfológicos e a massa de forragem acumulada pelo amendoim forrageiro, todavia o índice de área foliar no pré-pastejo não é alterado.

O amendoim forrageiro não deve ser utilizado sob pastejo intenso. Intensidades de pastejo de moderada a muito leniente proporcionam maior massa de forragem pré-pastejo e total acumulada, associada a menores intervalos entre pastejos.

\section{REFERÊNCIAS}

AFFONSO, A.B.; FERREIRA, O.G.L.; MONKS, P.L. et al. Rendimento e valor nutritivo da forragem outonal de amendoim forrageiro. Ciênc. Anim. Bras., v.8, p.385-395, 2007.
AMARAL, M.F.; MEZZALIRA, J.C.; BREMM, C. et al. Sward structure management for a maximum shortterm intake rate in annual ryegrass. Grass Forage Sci., v.68, p.271-277, 2013.

ARGEL, P.J.; KERRIDGE, P.J.; PIZARRO, E.A. Arachis pintoi: a multipurpose legume for sustainable land use. Cali, Colombia:Tropical Forage Program of CIAT, 2005. p.83-84.

BARBOSA, R.A.; NASCIMENTO JUNIOR, D.; EUCLIDES, V.P.B. et al. Capim-tanzânia submetido a combinações entre intensidade e frequência de pastejo. Pesqui. Agropecu. Bras., v.42, p.329-340, 2007.

CARVALHO, L.R. Interceptação luminosa, massa de raízes e acúmulo de forragem em Arachis pintoi $\mathrm{cv}$. Belmonte submetido a intensidades de pastejo. 2014. 79f. Dissertação (Mestrado em Ciência Animal e Pastagens) - Escola Superior de Agricultura "Luiz de Queiroz”, Universidade de São Paulo, Piracicaba, SP.

CARVALHO, P.C.F.; PRACHE, S.; DAMASCENO, J.C. O processo de pastejo: desafios da procura e apreensão da forragem pelo herbívoro. In: REUNIÃO ANUAL DA SOCIEDADE BRASILEIRA DE ZOOTECNIA, 36., 1999, Porto Alegre. Anais... Porto Alegre: SBZ, 1999. v.2, p.253-268.

CARVALHO, P.C.F.; TRINDADE, J.K.; SILVA, S.C. et al. Consumo de forragem por animais em pastejo: analogias e simulações em pastoreio rotativo. In: SILVA, S.C. et al. (Eds.). SIMPÓSIO SOBRE MANEJO DA PASTAGEM: intensificação de sistemas de produção animal em pasto 25., 2009, Piracicaba. Anais... Piracicaba: FEALQ, 2009. p.6193. 
FERREIRA, A.S. Desempenho agronômico, características morfofisiológicas e valor nutritivo da forragem de quatro genótipos de amendoim forrageiro sob corte. 2014. 76f. Tese (Doutorado em Ciência Animal e Pastagens) - Escola Superior de Agricultura "Luiz de Queiroz", Universidade de São Paulo, Piracicaba, SP.

FIALHO, C.A. Características morfogênicas $e$ estruturais de amendoim forrageiro (Arachis pintoi krapovickas \& Gregory cv. Belmonte) submetido a intensidades de pastejo sob lotação contínua. 2015. 122f. Tese (Doutorado em Ciência Animal e Pastagens) - Escola Superior de Agricultura "Luiz de Queiroz”, Universidade de São Paulo, Piracicaba, SP.

GOBBI, K.F.; GARCIA, R.; GARCEZ NETO, A.F. et al. Morphological and structural characteristics and productivity of brachiaria grass and forage peanut submitted to shading. Rev. Bras. Zootec., v.38, p.16451654, 2009.

GONÇALVES, J.O. Campos naturais da região da campanha do Rio Grande do Sul: características de suporte e sustentabilidade. Brasília: EMBRAPA CPPSUL, 1999. 30p.

LEMAIRE, G. The physiology of grass growth under grazing: tissue turnover. In: SIMPÓSIO INTERNACIONAL SOBRE PRODUÇÃO ANIMAL EM PASTEJO, 1997, Viçosa. Anais... Viçosa: Universidade Federal de Viçosa, 1997. p.117-144.

L'HUILLIER, P.J.; POPPI, D.P.; FRASER, T.J. Influence of structure and composition of ryegrass and prairie grass-white clover swards on the grazed horizon and diet harvested by sheep. Grass Forage Sci., v.41, p.259-267, 1986.

MACHADO, A.N.; SIEWERDT, L.; ZONTA. E.P. et al. Rendimento do amendoim forrageiro estabelecido sob diferentes arranjos populacionais de plantas em planossolo. Ciênc. Anim. Bras.,v.6, p.151-162, 2005.

MANUAL de adubação e de calagem para os estados do Rio Grande do Sul e de Santa Catarina. 10.ed. Porto Alegre: Sociedade Brasileira de Ciência do Solo / Comissão de Química e Fertilidade do Solo, 2004. 400p.

MENEZES, A.P.M.; ASSIS, G.M.L.; MATAVELI, M. et al. Genetic divergence between genotypes of forage peanut in relation to agronomic and chemical traits. Rev. Bras. Zootec., v.41, p.1608-1617, 2012.

NASCIMENTO, I.S.; MONKS, P.L.; VAHL, L.C. et al. Adubação PK e manejo de corte sobre a produção de biomassa de amendoim forrageiro. Rev. Bras. Agrociênc., v.16, p.41-50, 2010.

NUTRIENT requeriments of small ruminants. Washington: National Academy Press, 2006. 362p.
PARSONS, A.J.; CHAPMAN, D.F. The principles of pasture growth and utilization. In: HOPKINS, A. Grass: its production and utilization. Oxford: Blackwell Science, 2000. p.31-89.

PARSONS, A.J.; JOHNSON, I.R.; WILLIAMS, J.H.H. Leaf age struture and canopy photosyntesis in rotationally and continuously grazed swards. Grass Forage Sci., v.43, p.1-14, 1988.

PRACHE, S.; PEYRAUD, J. Préhensiblité de l' herbe pâturée chez lês bovins et lês ovins. INRA Prod. Anim., v.10, p.377-390, 1997.

RAO, I.M.; AYARZA, M.A.; GARCÍA, R. Adaptive atributes of tropical forage species to acid soils. III. Differences in plant growth, nutrient acquisition and nutriente utilization among $\mathrm{C} 4$ grasses and $\mathrm{C} 3$ legumes. J. Plant Nutr., v.18, p.2135-2155,1995.

RATTRAY, P.V.; THOMPSON, K.F.; HAWKER, H.; SUMMER, R.M.W. Pastures for sheep production. In: NICOL, A.M. (Ed.). Livestock feeding on pasture. New Zealand: Society of Animal Production, 1987.p.89-104. (Occasional Publication, 10)

SILVA, V.J.; DUBEUX JUNIOR, J.C.B.; TEXEIRA, V.I. et al. Características morfológicas e produtivas de leguminosas forrageiras tropicais submetidas a duas frequências de corte. Rev. Bras. Zootec., v.39, p.97102,2010

STOOBS, T.H. A comparison of zulu sorghum, bulrush millet and white panicum in terms of yield, forage quality and milk production. Aust. J. Exp. Agric. Anim. Husb., v.15, p.211-218, 1975.

TEIXEIRA, V.I.; DUBEUX JUNIOR, J.C.B.; SANTOS, M.V.F. et al. Aspectos agronômicos e bromatológicos de leguminosas forrageiras no nordeste brasileiro. Arch. Zootec., v.59, p.245-254, 2010.

TRINDADE, J.K.; SILVA, S.C.; SOUZA JUNIOR, S.J. et al. Composição morfológica da forragem consumida por bovinos de corte durante $o$ rebaixamento do capim-marandu submetido a estratégias de pastejo rotativo. Pesqui. Agropecu. Bras., v.42, p.883-890, 2007.

URBANO, D.; DÁVILA, C.; CASTRO, F. Efecto de la altura y frecuencia de corte sobre tres variedades de maní forrajero (Arachis pintoi) en el estado Mérida. I. Rendimiento y contenido de proteína cruda. Zootec. Trop., v.28, p.449-456, 2010.

VALENTIM, J.F.; ANDRADE, S.C.M.; MENDONÇA, H.A.; SALES, M.F.L. Velocidade de estabelecimento de acessos de amendoim forrageiro na Amazônia Ocidental. Rev. Bras. Zootec., v.32, p.15691577, 2003. 